D.O.I.: $10.3895 / \mathrm{S} 1808-04482009000300007$

\title{
PROCESSO DE NEGÓCIO DA PRODUÇÃO DE AÇO: MODELAGEM DO FLUXO PRODUTIVO ORIENTADO EM EVENTOS DISCRETOS
}

\section{STELL MANUFACTURING BUSINESS PROCESS: MODELLING THE PRODUCTION FLOW DRIVEN BY DISCRETE EVENT}

\author{
Marcos Ricardo Rosa Georges ${ }^{1}$; Antonio Batocchio ${ }^{2}$ \\ ${ }^{1}$ Pontifícia Universidade Católica de Campinas - PUC-Campinas - Brasil \\ marcos.georges@puc-campinas.edu.br \\ ${ }^{2}$ Universidade Estadual de Campinas - UNICAMP - Brasil \\ batocchi@fem.unicamp.br
}

\begin{abstract}
Resumo
Este artigo apresenta os modelos de processos de negócio da produção de aço feitos através de diagramas baseados na linguagem EPC (Event-driven process chain). Discussão e analises do resultado são feitas e sugestões são propostas neste trabalho. Também é feito uma revisão do conceito de processo de negócio, das ferramentas de modelagem de processo e das arquiteturas de referência, onde a arquitetura de referência ARIS é apresentada e que foi usada para produzir os modelos de processos detalhados neste trabalho.
\end{abstract}

Palavras-chave: processo de negócio; modelagem de processos de negócio; event-driven process chain; produção de aço; sistema de manufatura.

\section{Introdução}

No prefácio do volume 1806 da série Lectures Notes in Computer Science, dedicado exclusivamente ao tema Gerenciamento do Processo de Negócio, seus editores: Wil van der Aalst, Jörg Desel e Andreas Oberweis; escrevem, no primeiro parágrafo, que o conceito de Processo de Negócio está entre os tópicos "mais quentes" - hottest foi o termo usado - na prática e ciência dos sistemas de informação (WIL VAN DER AALST et al., 2000).

De fato, desde o início dos anos 90 o conceito de Processos de Negócio tem ganhado projeção e crescente importância no mundo acadêmico e nas empresas, seu estudo e aplicação estão cada vez mais profundos e diversificados, o que pode ser verificado pela grande quantidade de áreas do conhecimento que são correlatas e que contribuem para seu desenvolvimento. 
Nesse volume da série LNCS, seu conteúdo foi dividido em três grandes subconjuntos: Concepção dos Processos de Negócio, Análise e Formalismo dos Processos de Negócio e Sistemas e Aplicações dos Processos de Negócio.

O presente artigo se enquadra na terceira opção, pois é utilizado para o entendimento do sistema produtivo, reconhecer sua capacidade e identificar possíveis gargalos que impediriam a expansão do volume produzido e, posteriormente, desenvolver um modelo de simulação para representar o funcionamento da produção de aço em diferentes cenários.

\section{Processo de Negócio}

O conceito de processo de negócio está no centro da abordagem sistêmica utilizada atualmente para descrever e interpretar as organizações. Esta abordagem sistêmica reconhece as partes individuais da organização empresarial como parte de um todo integrado e é a tecnologia da informação, mais do que qualquer outro fator, que torna possível integrar uma empresa.

O conceito de Integração dos sistemas surgiu na década de 70 com o conceito de Manufatura Integrada por Computador (CIM), porém, no início, tal integração era apresentada somente no processo produtivo e não se estendia as outras áreas da organização, como setores administrativos. O conceito de integração nesta época era visto como uma questão tecnológica e não como uma questão organizacional.

A integração empresarial via sistemas de informação (segundo os conceitos CIM) até contribuiu para a melhoria da eficiência operacional, mas era feita sob orientação funcional e compreendia apenas tarefas produtivas, não sendo suficiente uma integração plena que seria exigida pelos novos padrões de competitividade que se revelariam após a década de 90 . E o problema não era uma 'insuficiência' tecnológica e sim de natureza organizacional.

Foi somente através do advento da orientação processual e com o amadurecimento da tecnologia de informação que os sistemas passaram a realmente integrar as diversas tarefas de uma organização, trazendo grandes saltos qualitativos no incremento da capacidade de competição. A figura 1 a seguir mostra a mudança de enfoque na Manufatura Integrada por Computador, cujo enfoque no início era para o "C" de computação e hoje é "I" de integração (NUMA, 2006).

É no centro dos esforços para integrar sistemas numa perspectiva orientada por processos que reside o conceito de processo de negócio, instrumento indispensável para reconhecer todos os agentes envolvidos nas atividades realizadas, bem como as informações e recursos utilizados por eles. 
O processo de negócio é a linguagem de representação dos processos internos e externos de uma organização que permite o projeto de sistemas de informação capazes de integrar toda a empresa numa perspectiva holística.

Figura 1 - Mudança no conceito CIM

CIM:Computer Integrated Manufacturing

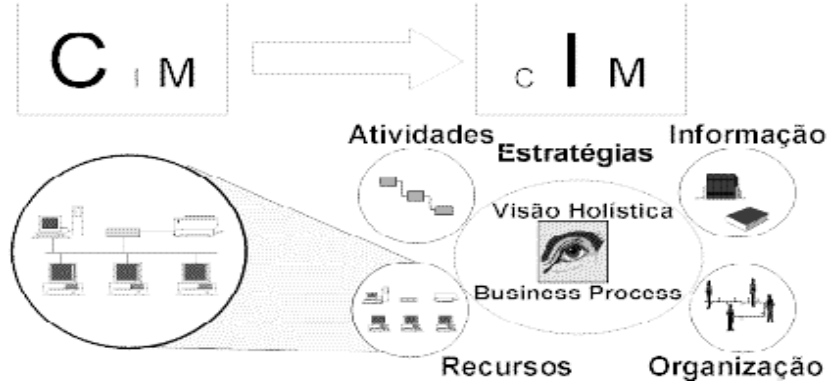

Fonte: NUMA (2006). http://www.numa.org.br

Segundo o professor Henrique Rozenfeld, o Processo de Negócio é um fenômeno que ocorre dentro das empresas, compreende um conjunto de atividades realizadas, associadas às informações que manipula, aos recursos que são utilizados e a estrutura organizacional da empresa. Forma uma unidade coesa e deve ser focalizado em um tipo de negócio, que normalmente está direcionado a um determinado mercado/cliente, com fornecedores bem definidos. Como recursos entendem-se: técnicas, métodos, ferramentas, sistemas de informação, recursos financeiros e todo o conhecimento envolvido na sua utilização. A organização engloba não somente os aspectos organizacionais e estruturais das empresas, como também os seus agentes, ou seja, as pessoas (NUMA, 2006)

Uma definição mais usual de processo de negócio é dada por Davenport (1994):

Um processo de negócio é um conjunto de atividades estruturadas e medidas destinadas a resultar num produto ou serviço, é, portanto, uma ordenação específica de atividades de trabalho no tempo e no espaço, com um começo, um fim, e inputs e outputs claramente identificados, dispostas segundo a ordem de precedência das atividades.

A figura 2 a seguir ilustra os processos de negócios típicos de uma empresa, onde cada área funcional possui seus processos de negócios característicos, chamados de processos de negócios intra-funcionais, e também mostram os processos de negócios inter-funcionais, que não se limitam a uma única área funcional.

Também é interessante ressaltar que a utilização de processos de negócios é usada em diversas abordagens modernas, como a metodologia de custo ABC (Activity-Based Costing), para a especificação dos processos exigida nas certificações da qualidade, para a reengenharia dos processos de negócio, para a definição de indicadores de desempenho, para a especificação de 
sistemas de informações e outras aplicações, mas, neste trabalho o interesse reside na análise do fluxo produtivo e estudo da capacidade instalada.

Figura 2 - exemplos de Processos de Negócios de uma empresa
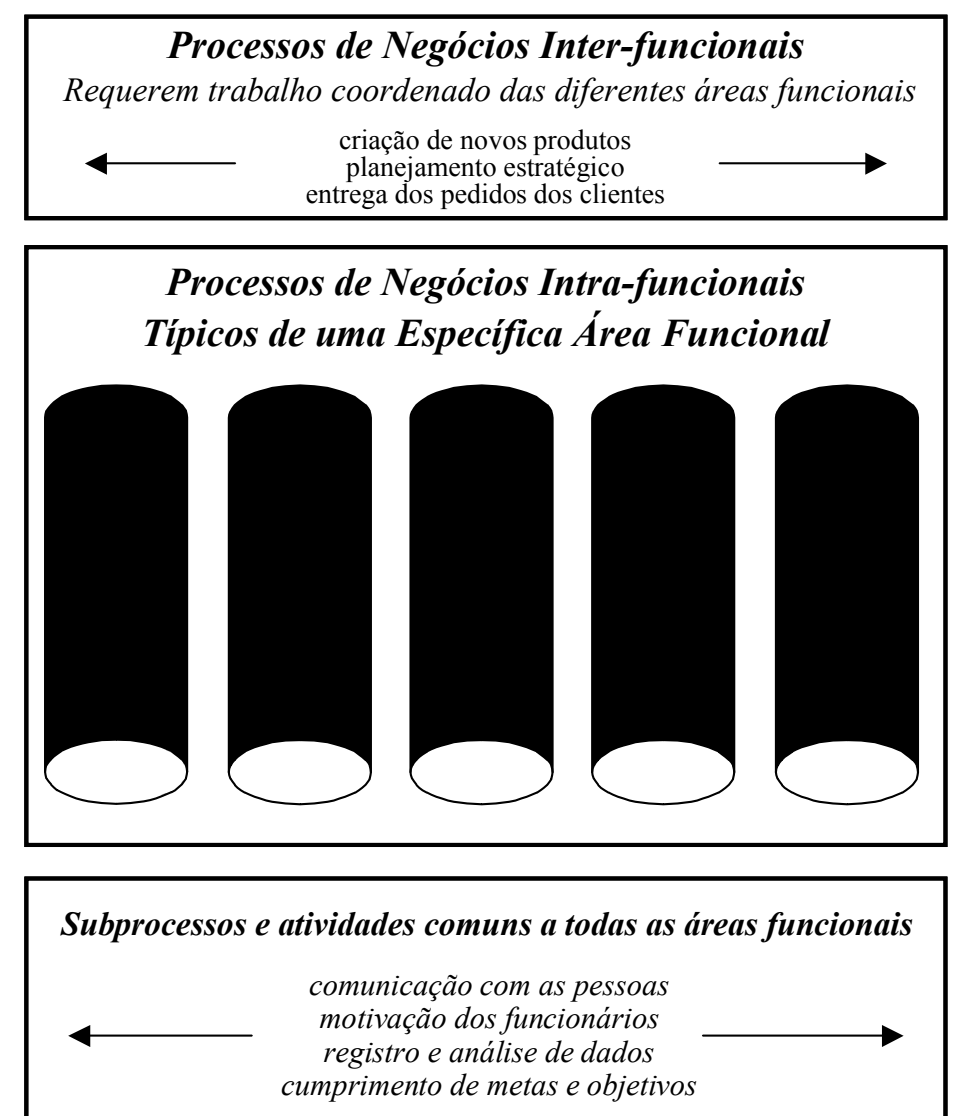

Fonte: Alter (1996)

\section{Modelagem dos Processos de Negócio}

A modelagem dos processos de negócios é um instrumento para a representação formal dos processos de uma empresa, de modo que o resultado seja interpretado sem ambigüidades e que todos os requisitos para a especificação de um sistema de informação sejam contemplados.

$\mathrm{Na}$ verdade, as metodologias de modelagem de processos de negócio são frutos da necessidade de especificar os requisitos de um sistema de informação segundo a orientação processual preconizada pela abordagem sistêmica atualmente em vigor.

As primeiras metodologias para a construção de Sistema de Informação que partiam de um modo de observação holístico surgiram com a Engenharia de Informação (GEORGES, 2001). Segundo a visão de James Martin (1989), um dos pioneiros na Engenharia da informação, o projeto de um sistema de Informação deve partir no nível organizacional mais alto e ser detalhado, na direção top down, até o nível de especificação do sistema, através das seguintes etapas:

- Planejamento estratégico das Informações da organização; 
- Análise das áreas de negócios;

- Projeto do sistema;

- Construção e Implementação;

Embora estivesse evidente a abordagem holística na engenharia da informação, a modelagem dos processos de negócio ainda não estava explícita na concepção dos sistemas de informação, mas era apenas uma questão de tempo, pois, técnicas de modelagem de processos já existiam (como fluxogramas e as rede de petri), no entanto, o que faltava, era uma abordagem para a modelagem de processos que fosse integrada com o desenvolvimento de sistemas de informação, o que só surgiu na virada da década de 80 para 90.

Um artigo de Grabowski et al. (1996) ilustra muito bem a evolução das metodologias de concepção e definição dos requisitos de um sistema de informação baseado no princípio da Engenharia da Informação de James Martin, mas com grande riqueza de detalhes no que tange a utilização das metodologias de modelagem dos processos de negócio, tal como ilustra a figura 3 a seguir.

Figura 3 - Geração de um sistema de informação a partir de um modelo da empresa

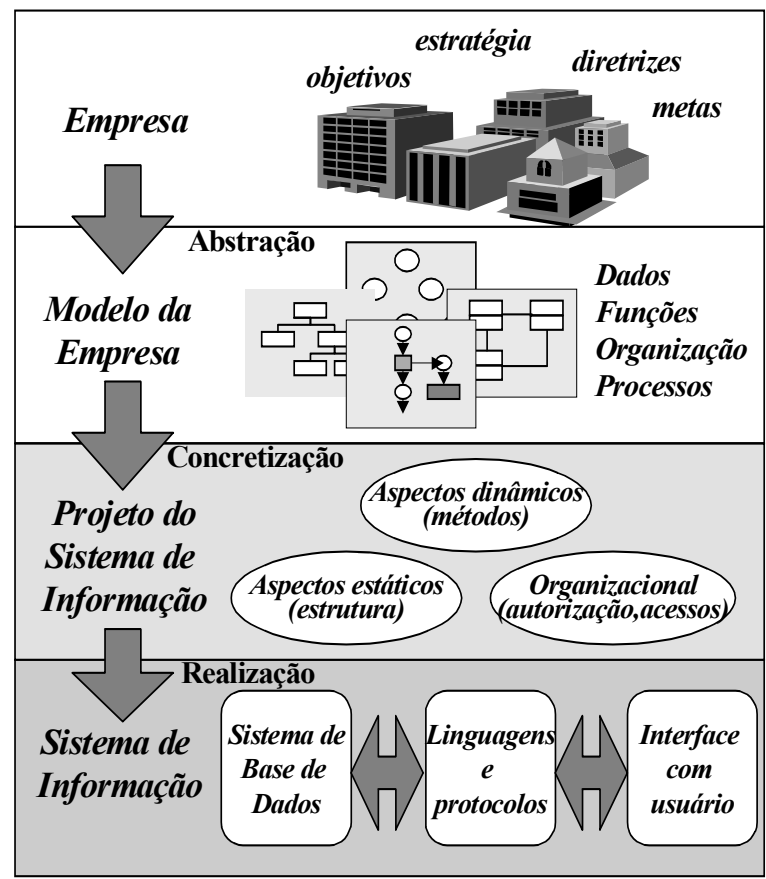

Fonte: Grabowski et al, (1996).

Observa-se claramente a utilização dos Processos de Negócios como formalismo utilizado para representar as regras e os elementos que modelam o Sistema de Manufatura no Sistema de Informação a ser construído.

Além deste aspecto da geração de modelos a partir de uma representação holística da empresa, Grabowski et al. (1996) também enfoca em detalhes os requisitos a serem definidos para a 
modelagem dos processos de negócio necessário para a concepção de um sistema de informação, esses requisitos são indicados na figura 4 a seguir, também extraída de Grabowski et al. (1996).

Figura 4 - Especificação dos requisitos de um sistema de informação baseados em um modelo de empresa

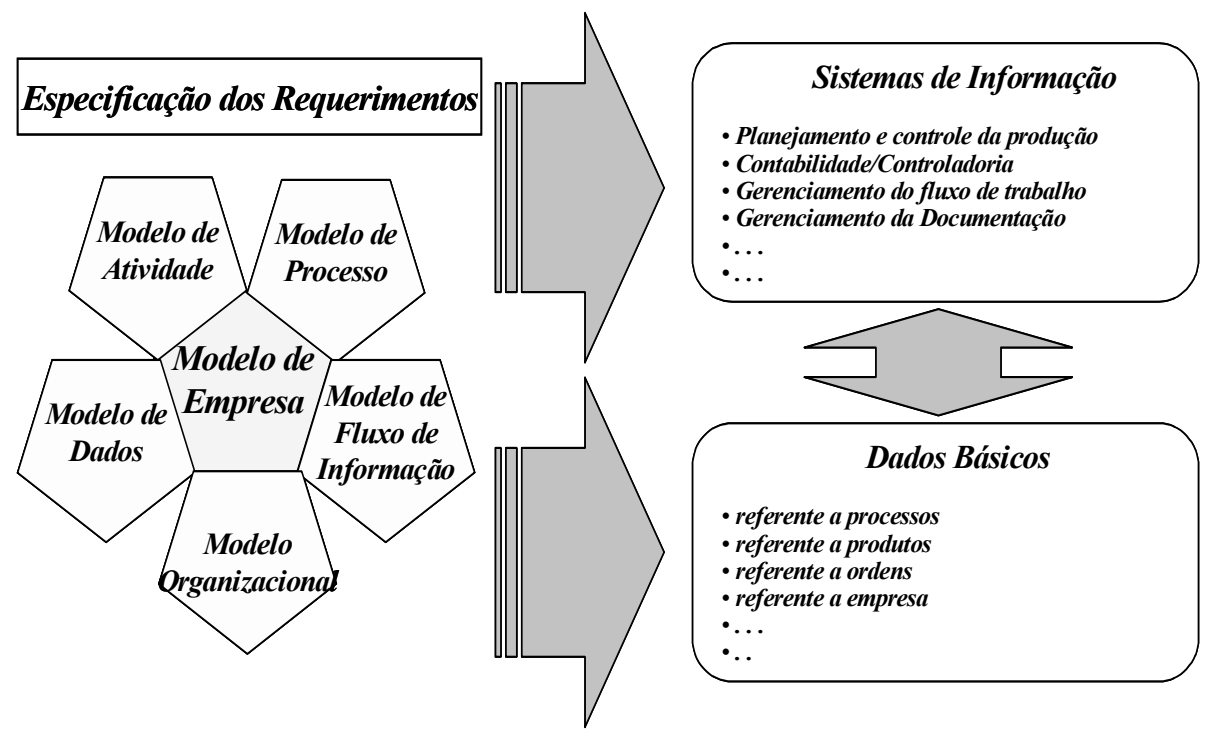

Fonte: Grabowski et al. (1996).

Esses requisitos referem-se aos aspectos que serão utilizados para a construção do sistema de informação, são eles: a definição de um modelo que representará a estrutura da organização; um modelo que representará as atividades da empresa; um modelo que representará os processos; um modelo que representará o fluxo de informação e um modelo de representação dos dados.

O conjunto destes diversos modelos de representação a ser usado para modelar os dados, as atividades, a estrutura organizacional e os processos de negócios e suas relações, bem como a metodologia de modelagem e diversos aspectos de implementação e refinamento dos processos modelados são definidos e reunidos nas chamadas Arquiteturas de Referência (Oliveira, M., 2000).

A modelagem de empresas baseados nestes elementos propicia a obtenção de uma maior compreensão dos processos internos da empresa, registra e documenta o conhecimento para posterior uso, possibilitando um maior racionamento dos recursos e maior confiabilidade no fluxo de informações. Também serve como base para análise do funcionamento de partes da empresa assim como sua simulação computacional, além de servir como base para tomada de decisões sobre operações e a organização da empresa, e, sobretudo, para o desenvolvimento e implantação de sistemas de informação integrados a partir de uma compreensão mais holística possível do negócio (NUMA, 2006).

São estes benefícios que motivaram o uso da modelagem dos processos de negócios como instrumento para análise do sistema produtivo da produção de aço, mais especificamente a 
documentação, o treinamento, o maior conhecimento dos processos, o estudo da capacidade e de gargalos e, posteriormente, a simulação.

\section{Arquiteturas de Referência}

A década de 90 assistiu a uma proliferação de metodologias de modelagem de empresa, ou arquiteturas de referências, destacando-se no meio acadêmico as arquiteturas de referência CIMOSA e IDEF $\varnothing$, e comercialmente destacam-se as arquiteturas ARIS e DEM.

A arquitetura CIMOSA (Open System Architecture of CIM) foi desenvolvida por um consórcio europeu que incluía um grupo de fornecedores de sistemas CIM, grandes usuários e acadêmicos. É uma arquitetura bem completa e compreende a modelagem (através de vistas) e uma metodologia de implantação CIM. Sua figura emblemática é chamada de cubo CIMOSA, onde cada dimensão do cubo representa um aspecto vital da modelagem e implementação que é contemplado nesta arquitetura (GEORGES, 2001).

A arquitetura IDEF $\varnothing$ (Integrated DEFinition Method) foi desenvolvida pela força aérea norte americana a partir da linguagem gráfica SADT (Structured Analysis and Design Technique), também desenvolvidas por eles. Na verdade a arquitetura IDEF $\varnothing$ é uma família de arquiteturas denominadas IDEF1, IDEF2,...IDEF5, cada qual destinada a modelar um aspecto específico da empresa (IDEF, 2006).

Comercialmente se tem a arquitetura DEM (Dynamic Enterprise Modeler), base para a implementação do sistema Baan $V$, da SSA Global que adquiriu a Baan Inc. É uma arquitetura simples, com uma visão das funções representadas por grandes círculos e com processos representados por elementos muito semelhantes aos da rede de petri (GEORGES, 2001).

A arquitetura ARIS (ARchitecture for Information System) foi desenvolvida pelo prof. August Scheer da Universidade de Saarbrücken na Alemanha, e hoje é comercializado pela empresa IDS-Scheer, que possui mais de 6000 empresas usuárias em 70 países.

A arquitetura ARIS também é utilizada pela empresa SAP na implementação do seu sistema de gestão integrado ERP líder de mercado e, portanto, é a arquitetura mais difundida comercialmente.

A metodologia ARIS descreve os processos empresariais sob quatro vistas distintas:

- Vista da organização;

- Vista dos dados;

- Vista das funções, e

- Vista dos Processos. 
A representação da arquitetura ARIS a seguir mostra as vistas que compõe os objetos de um processo de negócio, mais precisamente um processo de negócio é constituído dos seguintes objetos e suas relações: um processo que gera e consome um dado, executa uma determinada tarefa de uma função, que é executada por alguém em algum setor da organização (Scheer e Nuttgens, 2000). A figura 5 a seguir ilustra a arquitetura ARIS através da composição de suas vistas.

\section{Figura 5 - Arquitetura ARIS}

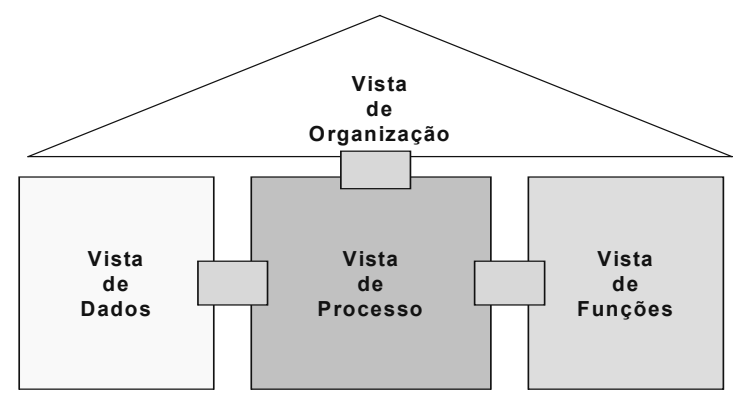

Fonte: Scheer e Nuttgens (2000)

A visão dos processos vê os processos de negócio através de uma cadeia de blocos construtores dispostos segundo a ordem temporal e de regras de precedência entre eventos e atividades subseqüentes. Decorre desta característica o próprio nome dado a este diagrama, chamado de EPC - Event-drive Process Chain - (SCHEER e NUTTGENS, 2000) tal como ilustrado na figura 6 a seguir.

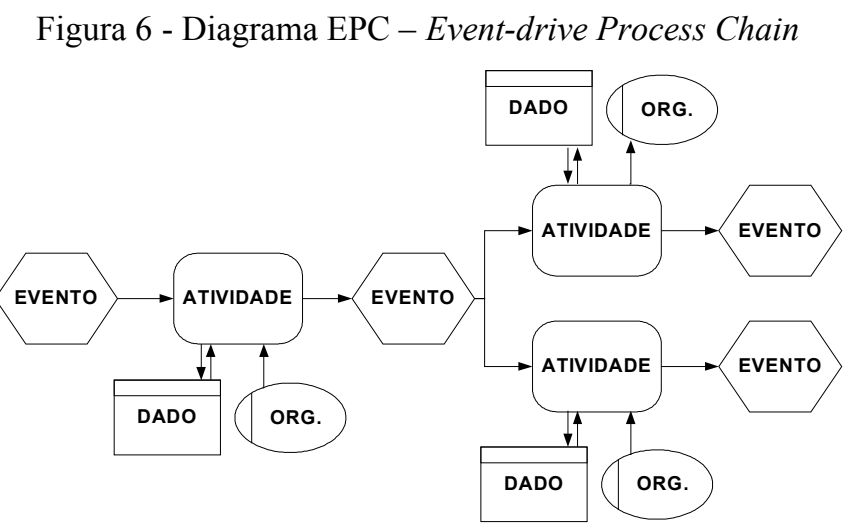

Fonte: Scheer e Nuttgens (2000)

A característica principal de um diagrama EPC é que os eventos ocorrem antes e depois de cada atividade, sendo, portanto, o evento que determina o funcionamento do diagrama. Este mecanismo simples de evento-atividade-evento é a essência do seu funcionamento, mas os 
diagramas EPC não se limitam a estes, ao contrário, contém outros visões e blocos que ampliam o alcance de sua representação.

A visão dos dados é destinada a modelar as informações que são geradas e consumidas durante as atividades. A representação formal dos dados é obtida com o uso de diagramas entidaderelacionamento (figura 7 a seguir) oriunda do estudo dos bancos de dados. Os dados se relacionam com os diagramas EPC através das atividades que, quando são realizadas, consomem e geram dados.

Figura 7 - Exemplo de um diagrama entidade-relacionamento

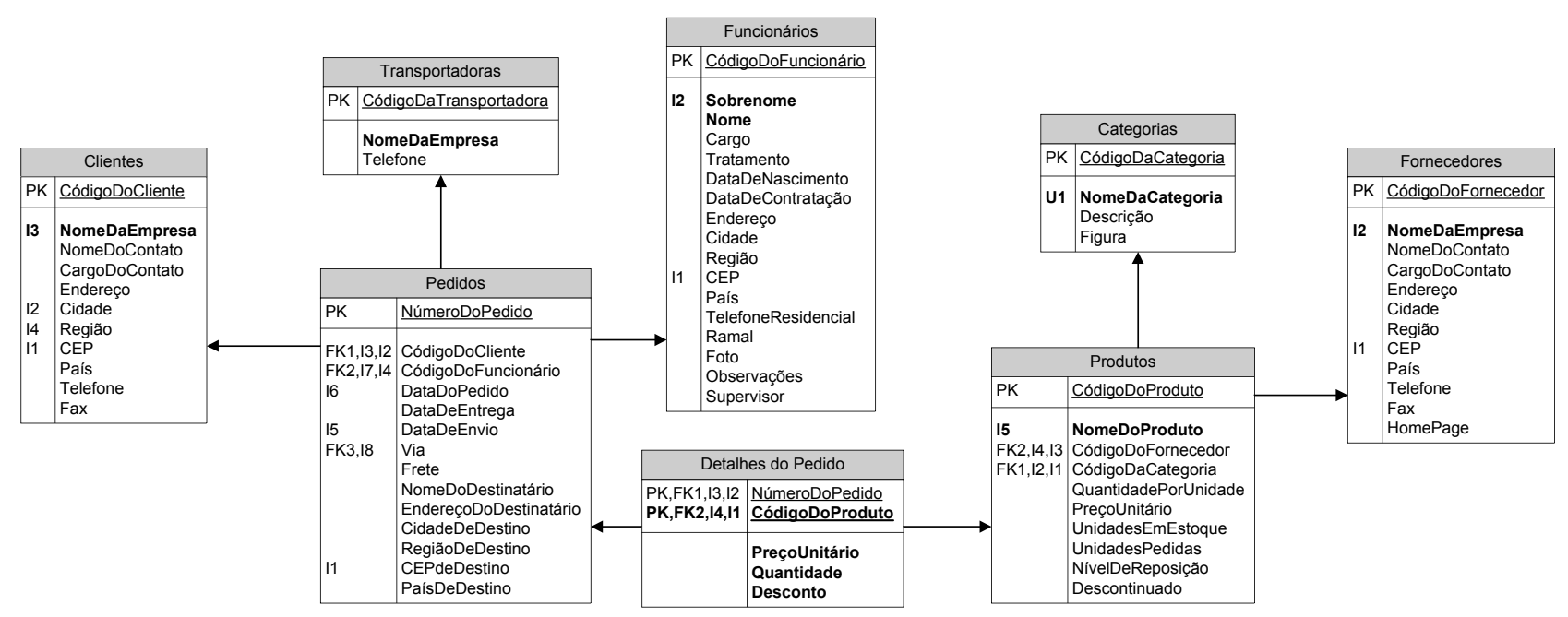

Fonte: exemplo disponível no software Microsoft Access

A vista da organização tem o objetivo de identificar cada colaborador da organização durante a realização de uma atividade, ou seja, cada atividade é realizada por alguém, que tem um lugar bem definido no organograma da empresa. Esta visão da organização é vital para definir direitos de acesso às informações do sistema, para identificar responsáveis por atividades e para o próprio fluxo de decisão em uma empresa.

A vista funcional é para definir as funções existentes dento da empresa; recebimento, expedição, controle de qualidade e produção são exemplos de funções existentes. Cada função definida possui um conjunto de processos descritos pelos diagramas EPC.

Assim, os diagramas EPC são capazes de representar um processo de negócio de modo amplo, incluindo em seu escopo de modelagem os aspectos dos dados envolvidos na sua realização, os aspectos organizacionais como hierarquia e relações interdepartamentais e os aspectos da própria função que empresa exerce quando realiza os processos de negócio.

Há, ainda, uma outra vista transversal a estas vistas descritas anteriormente, que é a vista da implementação, onde são definidas fases que vão desde a modelagem até a implantação do sistema na empresa. 
Todas estas vistas tornam os diagramas EPC e a arquitetura de referência ARIS capazes de representar as organizações com grande detalhe e sem perder sua característica essencial, sua visão sistêmica e processual. Mais além, é capaz de fornecer os requisitos necessários para o desenvolvimento de um banco de dados único capaz de apoiar a realização de todos os processos, além de mecanismos de controle dos processos e tudo mais que um sistema de informação necessita.

Tudo isso de modo rigoroso do ponto de vista formal, como linguagem de computação que necessita de verificação de consistência aliado com as facilidades de uma linguagem de fácil compreensão e menos formal como os fluxogramas.

Mas, para os propósitos deste trabalho, que se limitam ao estudo do fluxo produtivo e posteriormente se estenderá a simulação, a modelagem de todas as vistas se mostra desnecessária, restringindo o escopo do trabalho somente aos diagramas EPC.

\section{Modelagem dos Processos da Produção de Aço}

Inicia-se aqui a modelagem dos processos da produção de aço. Os dados sobre a siderúrgica onde a modelagem foi feita serão mantidos em sigilo, assim como algumas informações sobre o desempenho do processo produtivo, tais como: tempo de processamento, volume produzido, tamanho dos lotes e outras informações dessa natureza.

O primeiro ato de modelagem feito foi à representação da aciaria - unidade produtiva da siderúrgica com planta exclusiva a produção do aço - como uma grande caixa preta, sendo alimentada por sucata (e demais insumos de modo implícito) e tendo como saída os lingotes.

Esta representação simplista foi feita propositadamente como elemento emblemático que remetesse a essência da abordagem sistêmica.

Seguidamente, esta grande caixa preta foi desdobrada em cinco grandes atividades, tal como ilustra a figura 8 a seguir. Esta atividade de desdobramento em cinco grandes atividades foi feita a partir das divisões físicas existentes na planta industrial onde a produção do aço ocorre, ou seja, cada uma das cinco atividades ocorre em locais distintos e bem especificados. 


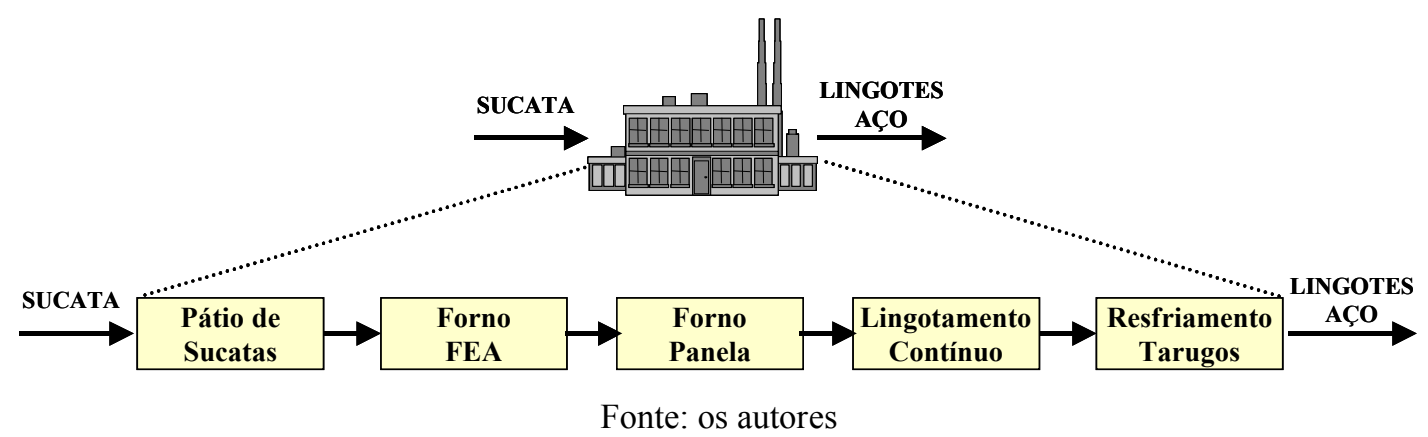

Outro aspecto que reforçou o desdobramento nestas cinco grandes atividades foi a existência de alguns recursos que são usados exclusivamente em cada atividade e também o fato de que cada atividade alimenta a atividade seguinte com um determinado produto bem especifico resultante dos processos internos a cada atividade. Essas características reforçam e facilitam a modelagem dos processos por constituírem subdivisões naturais do processo de produção de aço, sendo muito apropriada a sua utilização na modelagem.

Cada uma das cinco grandes atividades apresentadas pela figura 8 foi então modelada pelos diagramas EPC e estão apresentadas nas figuras 9, 10, 11 e 12, todas apresentadas a seguir. 
Figura 9 - Modelagem dos Processos no Pátio de Sucatas

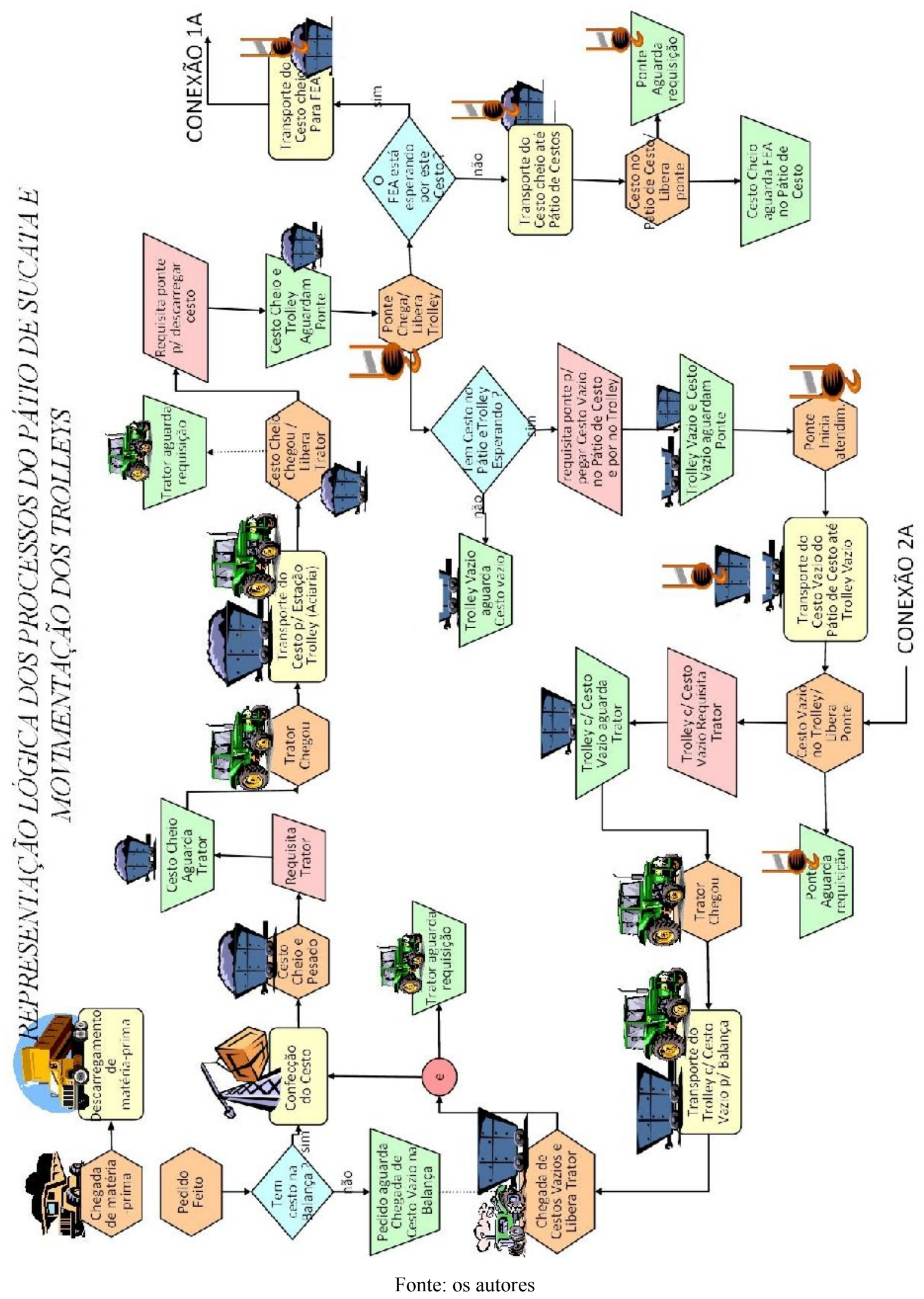


Figura 10 - Modelagem dos Processos do Carregamanto do Forno FEA

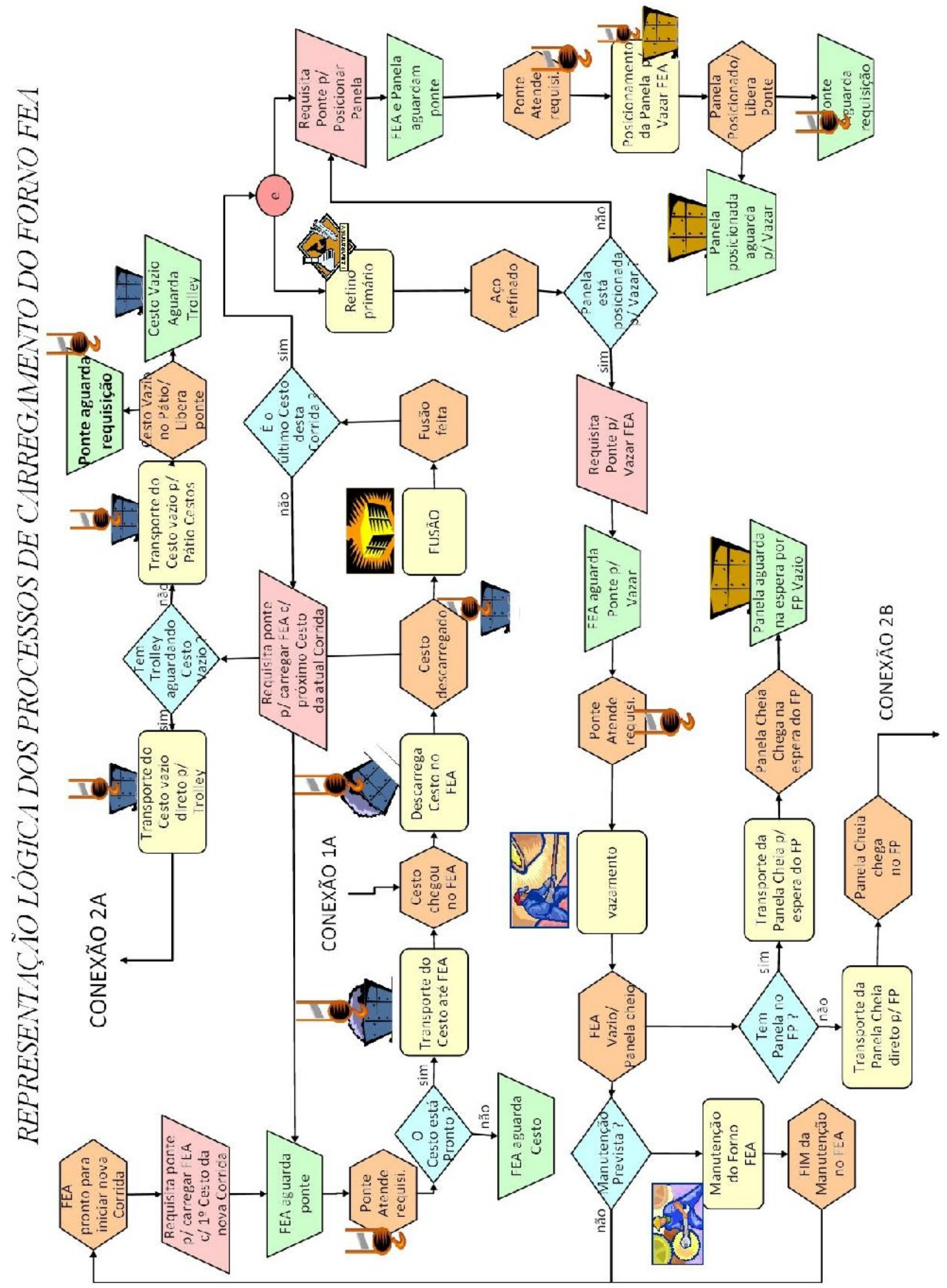

Fonte: os autores 
Figura 11 - Modelagem dos Processos do Forno Panela

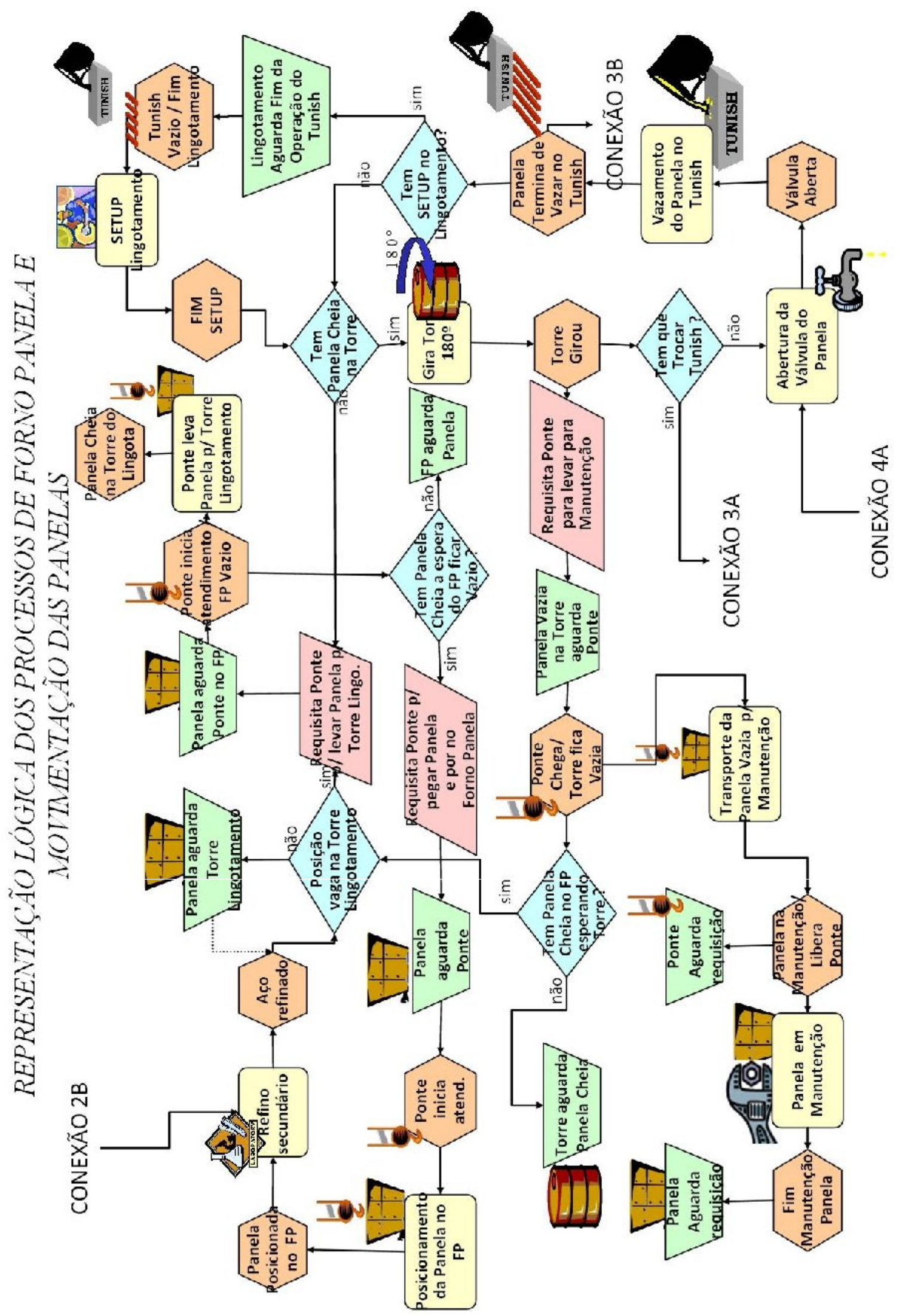

Fonte: os autores 
Figura 12 - Modelagem dos Processos do Lingotamento Contínuo e Resfriamento dos Tarugos

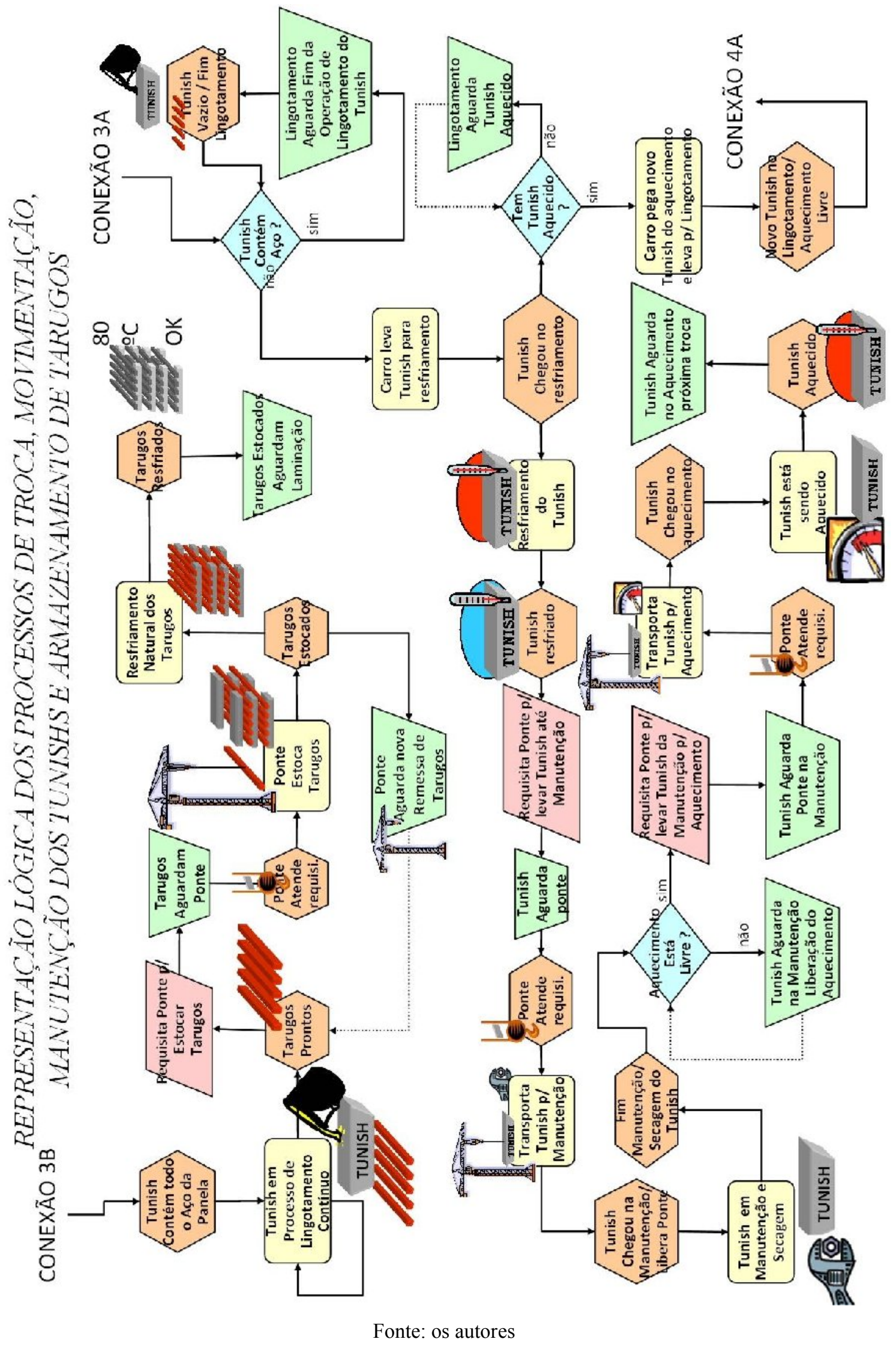




\section{Considerações Finais}

Inicialmente foi necessário fazer uma adaptação na linguagem EPC para representar os processos de negócio para fins de simulação. Não que a linguagem EPC fosse insuficiente para contemplar os aspectos relevantes para a simulação, mas sim como artifício para realçar um aspecto muito relevante que é implícito nos diagramas EPC originais: as filas de espera.

As filas são um dos elementos mais evidentes em um modelo de simulação, e quase sempre as medidas de desempenho estão associadas aos tempos de espera e tamanho da fila, só que as filas ficam implícitas nos diagramas EPC. Ao termino de uma atividade, o que dispara um evento, uma entidade pode deixar um atividade e se dirigir à atividade seguinte e pode, ou não, ficar em uma fila. Para saber se esta entidade está em uma fila ou não basta checar seu estado, que pode ser 'em processamento' ou 'aguardando', mas isto não é explicitado nos diagramas que constituem os modelos EPC, estão registrados internamente nas variáveis que registram o estado das entidades.

Sendo assim, foi adicionado um novo bloco construtor - o trapézio - que denota a existência de uma fila, seja para aguardar a vez de ser processado na máquina ou para aguardar a chegada de um equipamento de transporte.

A inclusão do bloco construtor da espera tornou evidentes os pontos que podem atrasar o fluxo produtivo devido esperas. E cada ponto de espera foi objeto de analise para se identificar o motivo de sua ocorrência.

Observou que diversos motivos provocam as esperas, desde a de falta de recurso, como no caso de trolleys para transporte ou da ponte rolante; também foi observada a ocorrência de esperas devido a falta de sincronismo entre as atividades e também devido a restrição da própria capacidade produtiva de algumas máquinas.

Esta analise qualitativa dos motivos das esperas já foi o suficiente para a elaboração de planos de ação a fim de aumentar a capacidade produtiva sem a necessidade de investimentos. Ações como sincronismo das remessas de aço, redefinição das prioridades da ponte rolante e realocação de alguns recursos já surtiam efeitos satisfatórios na capacidade produtiva.

Outro recurso que se mostrou válido é a utilização de ilustrações ao lado dos blocos construtores de modo que seja feita uma associação direta entre o símbolo e a tarefa ou recurso que é utilizado. Ilustrações de trolleys, pontes rolantes, cestos, tarugos, etc..., tornam o modelo mais fácil de ser interpretado pelos funcionários que estão cotidianamente em contato direto com o sistema produtivo. Esta facilidade torna a tarefa de validação do modelo mais simples e segura.

Simples pelo fato de não ser necessário o treinamento intensivo do funcionário para entender modelos formais dispostos na vertical e sem auxílio de ilustrações. Mesmo sendo modelos formais, esta disposição mais livre, de modo que todo o fluxo esteja contido em uma única página, facilita o 
entendimento global de todo o processo. Se estivesse disposto na vertical seriam necessários de três a quatro páginas para conter cada grande atividade, o que poderia comprometer esta visão global tanto desejada dos processos modelados.

O uso das ilustrações também facilita este entendimento global, pois ao visualizar todo o modelo não se perde a associação de cada atividade com o recurso que esta está associada, sendo possível uma olhar para todo o processo de modo global sem perder a identificação dos detalhes. Se não houvesse a ilustração seria necessário ler o texto de cada bloco construtor e, ao focar os olhos para realizar a leitura, involuntariamente e inevitavelmente o ser humano perde a visão global em decorrência da leitura do texto inserido no bloco construtor. E quanto maior for o modelo do processo, pior será obter essa visão global sem o auxílio das ilustrações.

Em decorrência da facilidade de entendimento dos modelos de processos por parte dos funcionários da siderúrgica torna-se mais segura a validação dos modelos junto a eles. Os funcionários ficam mais desinibidos ao identificar possíveis erros nos modelos e todo o processo de apresentação do modelo para os funcionários fica mais fácil e produtivo devido ao uso das ilustrações.

\begin{abstract}
This article shows the modeling of the business process steel manufacturing made through suitable diagrams of EPC (event-driven process chain) language. Discussion and analysis of the results is made and suggestions are proposals. Also a revision of the concepts of business process modeling and reference architectures is made, which the reference architecture ARIS is presented with more details.
\end{abstract}

Key-words: business process modeling, event-driven process chain, business process management, steel manufacturing, simulation systems

\title{
Referências Bibliográficas
}

ALTER, STEVEN - Information Systems: a management perspective, $2^{\mathrm{a}}$ ed., The Bejamin/Cummings Publising Company, Menlo Park, 1996.IDAVENPORT, T. H. - Reengenharia de Processos: como inovar na empresa através da tecnologia da informação, Editora Campus, Rio de Janeiro, 1994.

GEORGES, M. R. R. - Contribuições sobre a Utilização de Sistema de Informação na Formulação do Planejamento Estratégico nos Sistemas de Manufatura. Dissertação de Mestrado, Unicamp, 2001.

GRABOWSKI, H.; GREIN, G.; Milde, P.; Webwr, U. - Conceptual desing of information systems based on enterprise modelling. In: Modelling and Methodologies for Enterprise Integration. London. UK : Chapman \& Hall, 1996. p. 113.

IDEF $\varnothing$ - Home Page - http://www.idef.com < acessado em 29/12/2006>.

MARTIN, JAMES - Engenharia da informação . Prentice Hall, New Jersey, USA, 1989. 
NUMA - Núcleo de Manufatura Avançada - http://www.numa.org.br < acessado em 26/12/2006>.

OliveirA, C. M. - Protótipo de um Ambiente de Modelagem de Empresa - Dissertação de Mestrado, Unicamp, 2000 .

SCHEER, A.W. \& NÜTTGENS, M. - ARIS Architecture and Reference Models for Business Process Management in Business Process Management, Lectures Notes in Computer Science, vol. 1806, Spring-Verlag Berlin Heidelberg, 2000 .

WIL VAN DER AALST et al. (Eds.): Business Process Management, Lectures Notes in Computer Science, vol. 1806, Spring-Verlag Berlin Heidelberg, 2000.

\section{Dados dos autores:}

Nome completo: Marcos Ricardo Rosa Georges

Filiação institucional: Pontifícia Universidade Católica de Campinas

Departamento: Centro de Economia e Administração

Função ou cargo ocupado: Professor Doutor em regime de dedicação integral a pesquisa e ensino Endereço completo para correspondência: PUC-Campinas, CEA, Nupex, Rod. Dom Pedro I, Km 136, Parque das Universidades, Campinas-SP, CEP 13086-900

Telefones para contato: (19) 3343-6776

e-mail: marcos.georges@puc-campinas.edu.br

\section{Nome completo: Antonio Batocchio}

Filiação institucional: Universidade Estadual de Campinas

Departamento: Faculdade de Engenharia Mecânica - Departamento de Engenharia de Fabricação Função ou cargo ocupado: Professor Doutor em regime de dedicação integral a pesquisa e ensino. Endereço completo para correspondência: DEF-FEM-Unicamp, Rua Mendeleiv, s/n, Campinas-SP, CEP 13083-852

Telefones para contato: (19) 3521-7999

e-mail: batocchi@fem.unicamp.br

Recebido para publicação em: 03/07/2009

Aceito para publicação em: 03/09/2009 